\title{
PENERAPAN E-COMMERCE PADA WEBSITE BERBASIS CONTENT MANAGEMENT SYSTEM PADA ICHIRO
}

\author{
Abid Ulya Aziz ${ }^{1)}$, Lauw Li Hin ${ }^{2)}$ \\ ${ }^{1}$ Sistem Informasi, Fakultas Teknologi Informasi, Universitas Budi Luhur \\ 1,2 Jl. Raya Ciledug, Petukangan Utara, Kebayoran Lama, Jakarta Selatan 12260 \\ E-mail : abidulyaaziz@gmail.com ${ }^{1)}$, lihin@budiluhur.ac.id ${ }^{2}{ }^{2}$
}

\begin{abstract}
Abstrak
Penggunaan sistem e-commerce dapat menguntungkan banyak pihak, baik pihak konsumen, produsen maupun penjual. Dalam Konsep online shopping ini mengadakan banyak fasilitas dan kelebihan jika dibandingkan dengan rancangan belanja yang konvensional. Pada toko sparepart sekaligus bengkel motor, Ichiro Motor saat ini hanya menerapkan konsep belanja yang konvensional. Dimana penjualannya hanya berdasarkan pelanggan dengan cara mendatangi langsung Ichiro Motor dan dalam melakukan promosi pihak Ichiro Motor masih menggunakan selembaran pamflet yang akan dirasakan kurang menyuguhkan informasi yang sangat tepat mengenai produk yang akan ditawarkan kepada para konsumen. Selain itu juga, dalam pembukuan untuk pembuatan laporan rekapitulasi penjualan masih dilakukan secara manual hingga pengolahan data laporan penjualan masih lambat dan belum terperinci dengan baik. Untuk mengatasi permasalahan tersebut maka di rancang website e-commerce berbasis content management system yang akan mudah digunakan. Adapun pendekatan yang digunakan penulis yaitu observasi, wawancara, dan dokumentasi. Hasil dari penelitian adalah website penjualan yang berbasis content management system dapat digunakan pada media promosi dan meningkatkan penjualan serta memasarkan produk secara luas, dan juga website yang dapat mudah di gunakan baik dari sudut pandang pelanggan maupun admin, pada Website Berbasis Content Management System di Ichiro Motor.
\end{abstract}

Kata kunci: website, e-commerce, penjualan, Ichiro Motor, content management system.

\section{PENDAHULUAN}

E-Commerce merupakan suatu toko online yang memiliki suatu konsep yang berkembang dalam dunia perinternet. Pemakaian sistem ini dapat menguntungkan berbagai banyak pihak, baik dari pihak konsumen,maupun dari pihak produsen atau penjual[1]. Selain itu proses transaksi akan sangat mempermudah proses menjadi lebih cepat, konsep toko online atau e-commerce akan dapat memotong banyak biaya operasional karena penjual tidak diharuskan untuk memiliki toko fisik. Kehadiran $e$ commerce sebagai media transaksi yang tentunya akan dapat menguntungkan berbagai banyak pihak, baik dari pihak konsumen, maupun dari pihak produsen atau penjual.Prosesnya juga dapat dilakukan secara efisien dalam mengehemat biaya, waktu dan juga tenaga.

Ichiro Motor adalah salah satu toko yang bergerak di bidang penjualan sparepart, khususnya penjualan sparepart motor. Di toko ini cara pemasarannya sampai saat masih kurang karna dalam penjualannya hanya sebatas pada wilaya sekitaran toko saja.

Menurut peneliti yang bernama Wahyunningrum (2015) yang berjudul "Implementasi dan pengujian Web E-commerce Produk Unggulan Desa” bermula dengan adanya kreatifitas produk dari sebuah desa yang melahirkan produk unggulan dengan kualitas terbaik.[2]
Perbedaan dari penelitian yang saya review adalah tentang bagaimana memasarkan stock lama agar tidak menumpuk di gudang.

Berdasarkan latar belakang yang telah dijelaskan, maka penulis mengindentifikasi masalah yang ada pada Ichiro Motor sebagai berikut :

a. Dengan semakin ketatnya persaingan dan adanya berbagai tuntutan dari pasar yang berdampak pada turunnya pendapatan.

b. Ruang lingkup penjualan yang masih terbatas diseputaran toko yaitu di Tangerang Selatan.

c. Stok yang tidak terpantau dengan baik dan terjadinya penumpukan barang pada gudang.

Adapun tujuan dari penulisan dan fungsi dari penelitian yang sedang di kerjakan, sebagai berikut :

a. Membuat website penjualan agar dapat membantu pelanggan mengetahui semua produk yang tersedia tanpa harus mendatangi langsung ke toko dan dapat lebih menghemat waktu.

b. Menyediakan keranjang pembelian yang dapat secara otomatis akan tersimpan sehingga menghasilkan laporan lebih akurat.

c. Memudahkan sebagai pelaku usaha dalam melakukan pemasaran produknya secara luas. 
Pada batasan masalah ini penulis akan membahas :

a. Metode dalam membangun website $e$ commerce

b. sampai dengan menjadikan sebuah laporan.

c. Di dalam sebuah website penjualan ini juga meliputi proses pembelian, pembayaran, pengiriman, serta proses cetak laporan.

\section{METODE PENELITIAN}

Untuk melakukan penelitian ini penulis menggunakan proses penelitian sebagai berikut :

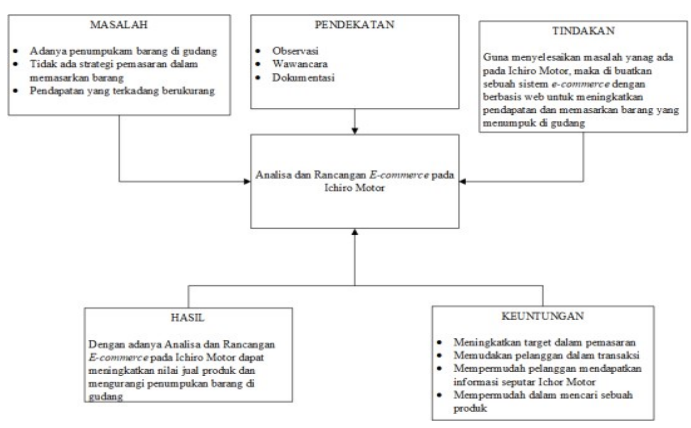

Gambar 1. Metode Penelitian

Pada gambar 1 merupakan gambaran kondisi dari Metode Penelitian yang di gunakan dalama membuat website e-commerce pada Ichiro Motor

\subsection{Wawancara}

Proses penulisan dalam mengumpulkan datadata yang dibutuhkan memerlukan metode wawacara langsung dengan pemilik toko dan karyawan. Melalui metode wawancara ini penulis mendapatkan bagaimana alur proses bisnis penjualan pada Ichiro Motor serta masalahnya.

\subsection{Observasi}

Proses penulisan selanjutnya yaitu dengan cara mengamati langsung proses penjualan yang terjadi di toko guna mendapatkan data yang jelas dan lengkap.

\subsection{Dokumentasi}

Penulis pengumpulan data berkas atau dokumen yang ada di Ichiro Motor sebagai sumber dan bagi peneliti seperti nota ataupun laporan penjualan.

\subsection{Implementasi}

Sesudah sistem dilakukan serangkaian testing memastikan sistem berjalan dengan baik, setelah itu menerapkan sistem yang sudah di uji kepada Ichiro Motor.

\subsection{Analisa Proses Bisnis}

Analisa proses bisnis adalah menganalisa proses bisnis dan aktivitas yang sedang berjalan pada ichiro motor, dengan perangkat yang digunakan untuk melakukan suatu analisa proses bisnis adalah activity diagram.

\section{HASIL DAN PEMBAHASAN}

\subsection{Business Model Canvas}

Business Model Canvas yaitu sebuah gambaran yang sama untuk memvisualisasikan, menilai, dan mengubah rancangan model bisnis. Dalam mengembangkan sistem E-Commerce peneliti yang menggunakan metodologi Business Model Canvas untuk menganalisa sebuah permasalahan dan kebutuhan Ichiro Motor[3]. Tujuan dari penelitian ini adalah untuk mengetahui bagaimana strategi usaha yang tepat dalam mengembangkan usaha dari ichiro motor menggunakan sistem E-Commerce. Business

Model Canvas yang terjadi pada ichiro motor, seperti dibawah :

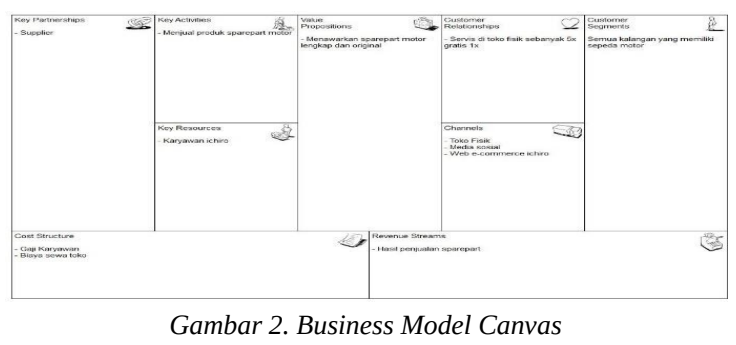

Pada Gambar 2 merupakan Business Model Canvas (BMC) yang digunakan oleh Ichiro Motor

\subsection{Activity Diagram}

Activity Diagram ialah diagram yang digunakan untuk menggambarkan sebuah alur aktivitas dari suatu proses[4]. Berikut ini merupakan activity diagram usulan yang dibuat peneliti pada ichiro motor:

a. Proses Pendaftaran

Setiap pelanggan yang belum memiliki akun pada website Ichiro Motor harus mendaftar terlebih dulu.

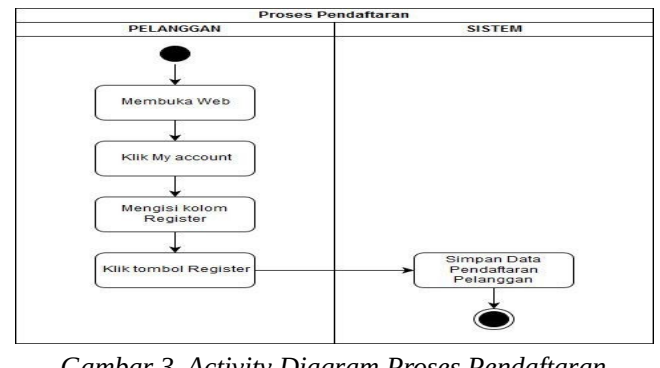


Pada Gambar 3 merupakan Activity Diagram proses pendaftaran dari Ichiro motor

b. Proses Pemesanan Barang

Untuk membuat sebuah pemesanan, pelanggan terlebih dahulu dapat klik My account lalu login, selanjutnya memilih produk, dan menentukan jumlah yang akan dibeli. Setelah itu dapat klik tombol add to cart. Apabila pelanggan ingin menambah sebuah produk, pelanggan dapat kembali lagi untuk memilih produk yang ada, jika tidak pelanggan selanjutnya dapat kembali ke proses checkout dan mengisi billing details, lalu pelanggan klik place order dan sistem akan mengirim email ke pelanggan sebagai konfirmasi dan menyimpan data pemesanan barang.

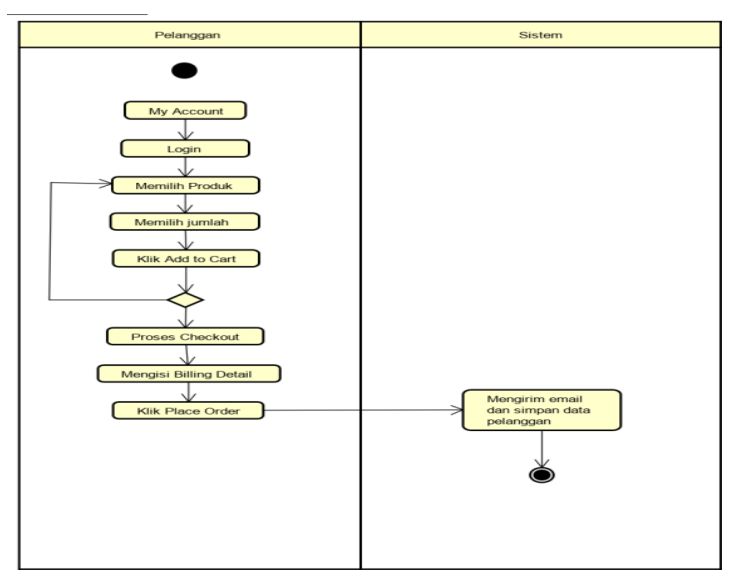

Gambar 4. Activity Diagram Pemesanan Barang

Pada gambar 4 merupakan Activity Diagram

Pemesanan Barang dari website Ichiro Motor

c. Proses Confirm Payment

Pelanggan melakukan pembayaran lalu pelanggan mengklik Confirm Payment lalu memilih bank transfer dan pilih transfer date lalu mengisi transfer time. Pelanggan menginput bukti pembayaran yang sudah dilakukan dengan cara mengupload bukti dari pembayaran tersebut, lalu pelanggan klik tombol submit. Sistem akan otomatis menyimpan data pembayaran.

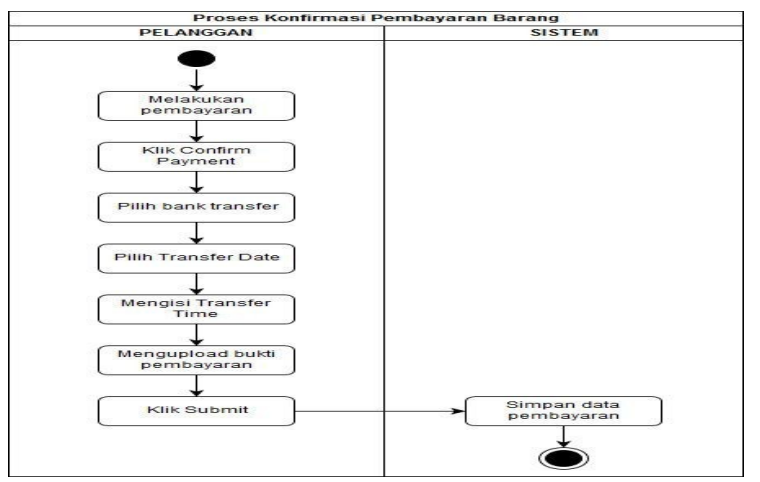

Gambar 5. Activity Diagram Konfirmasi Pembayaran
Pada gambar 5 merupakan Activity diagram konfirmasi pembayaran dari Ichiro motor

d. Proses Laporan

Setiap bulan admin akan membuat laporan penjualan, laporan pengiriman, laporan pembayaran, laporan pemesanan barang dan laporan rekapitulasi, yang kemudian admin menyerahkan laporan tersebut ke owner.

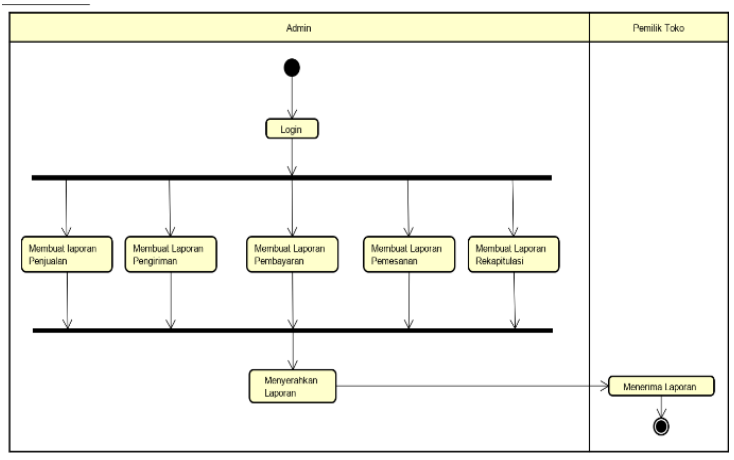

Gambar 6. Activity Diagram Laporan

Gambar 6 merupakan Activity Diagram Laporan dari website ichiro motor

e. Proses Tambah Produk

Admin diharuskan login terlebih dulu kemudian mengklik products kemudian admin memilih add new dan mengisi kolom dari add new product, Bila admin sudah selesai menambahkan sebuah produk, admin mengklik tombol terbitkan dan sistem akan secara langsung meyimpan data produk secara otomatis.

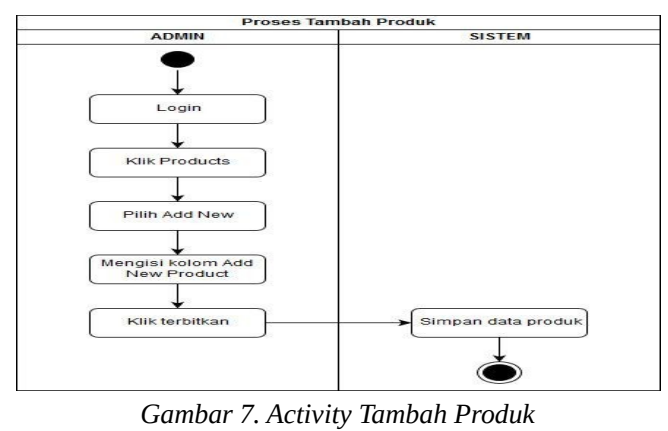

Pada gambar 7 merupakan Activity Tambah Produk pada website Ichiro Motor

f. Proses Tambah Kategori

Admin akan login terlebih dahulu lalu mengklik products kemudian admin dapat memilih categories lalu memasukan pada kolom add new category. Apabila admin sudah selesai menambah kategori, lalu admin mengklik tombol add new category dan sistem secara otomatis akan meyimpan data kategori. 


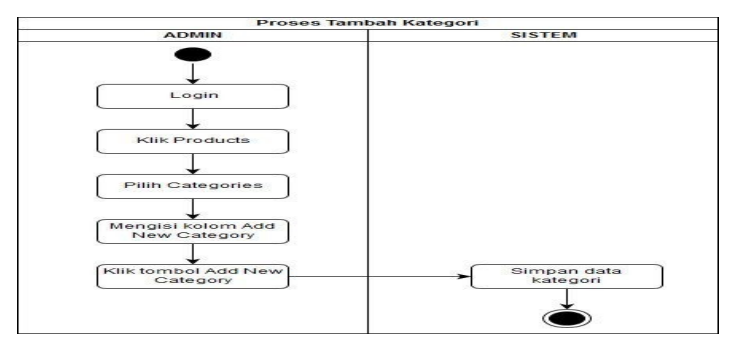

Gambar 8. Activity Diagram Tambah Kategori

Pada gambar 8 merupakan Activity Diagram Tambah Kategori dari ichiro motor

g. Proses Input Resi

Admin melakukan login terlebih dahulu lalu mengklik WooCommerce lalu admin memilih orders dan memilih orderan yang akan di inputkan resinya. Berikutnya admin memilih add tracking info setelah itu konsumen memilih provider, kemudian mengisikan tracking number dan yang terakhir dapat pilih date shipped. Bila sudah selesai admin dapat klik update lalu sistem secara otomatis akan meyimpan data.

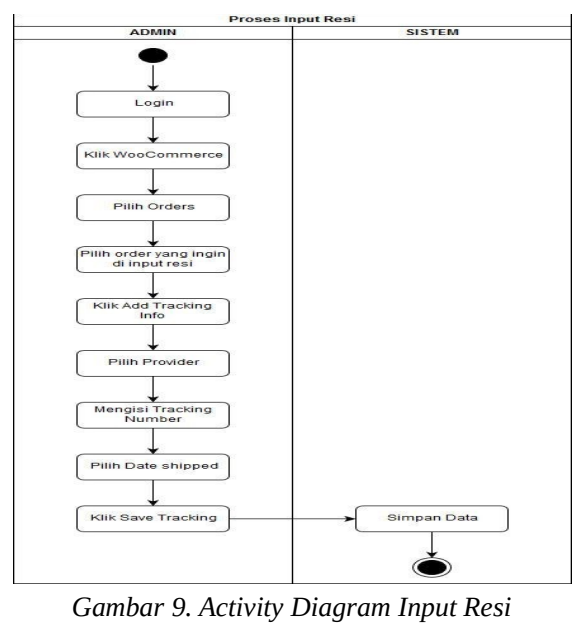

Pada Gambar 9 merupakan Activity diagram Input Resi Ichiro Motor

\subsection{Use Case Diagram}

Use Case Diagram merupakan diagram yang digunakan untuk menggambarkan sebuah relasi antara sistem dengan actor upaya mempermudah dalam pembentukan sistem[5]. Berikut adalah Use Case Diagram yang dibuat oleh peneliti :

a. Use Case Master

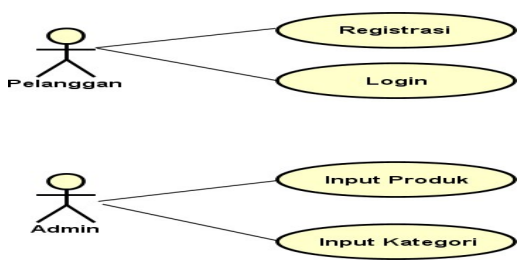

Gambar 10. Use Case Master
Pada Gambar 10 merupakan Use Case Master dari ichiro motor

b. Use Case Transaksi

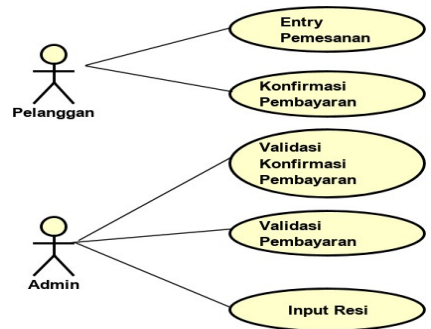

Gambar 11. Use Case Transaksi

Pada gambar 11 merupakan Use Case Transaksi dari Ichiro Motor

c. Use Case Laporan

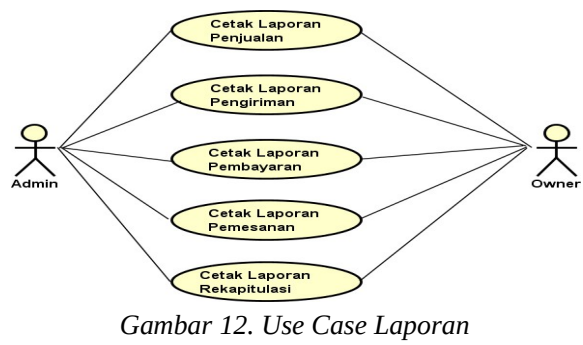

Pada gambar 12 merupakan Use Case Laporan dari ichiro motor

\subsection{Rancangan Basis Data}

Rancangan Basis Data yang mau digunakan oleh peneliti adalah Class Diagram, merupakan suatu penggambaran setiap objek atau data yang terdapat pada suatu sistem[6]. Berikut ini merupakan Class Diagram yang dibuat oleh peneliti :

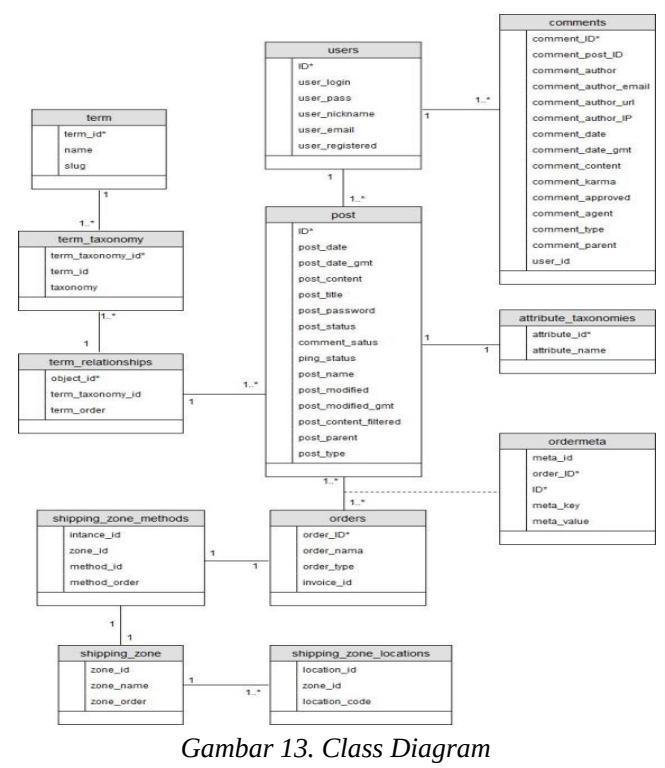


Pada gambar 13 merupakan Class Diagram dari website Ichiro motor

\subsection{Struktur Tampilan Menu}

a. Front End

Berikut adalah struktur tampilan menu pelanggan Ichiro Motor :

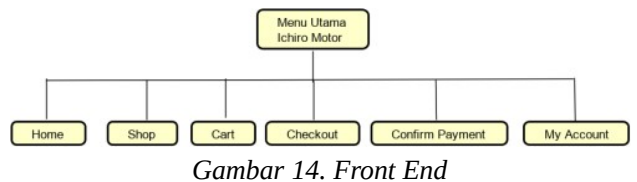

Pada Gambar 14 merupakan Front End dari website Ichiro Motor

b. Back End

Berikut adalah struktur tampilan menu admin Ichiro Motor:

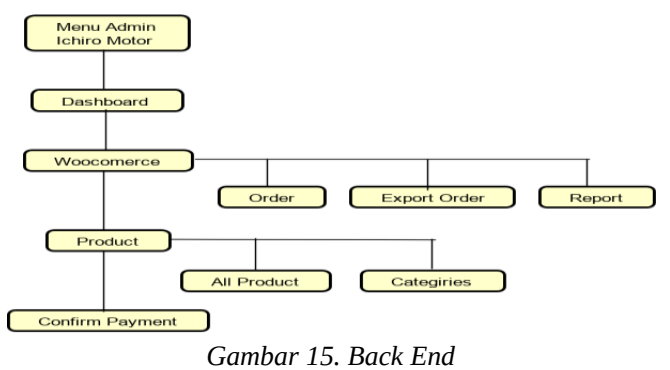

Pada gambar 15 merupakan Back End dari Ichiro motor

\subsection{Rancangan Layar}

a. Rancangan Layar Menu Utama

Berikut merupakan sebuah rancangan layar pada menu pelanggan ketika sudah berada di website ichiromotor.com :

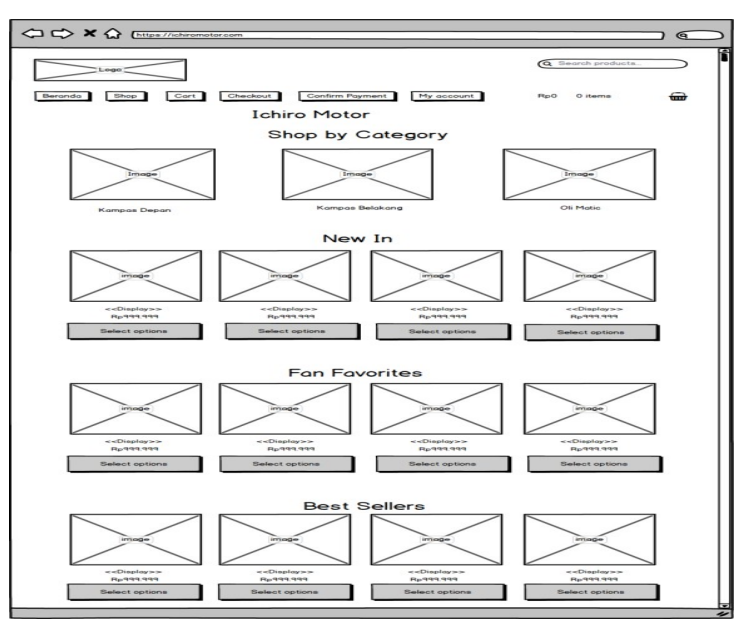

Gambar 16. Rancangan Layar Menu Utama

Pada gambar 16 adalah Rancangan Layar Menu Utama b. My Account

Berikut adalah sebuah rangkaian layar apabila pelanggan ingin melakukan login yang sudah memiliki akun pada ichiro motor dan register yang belum mempunyai akun :

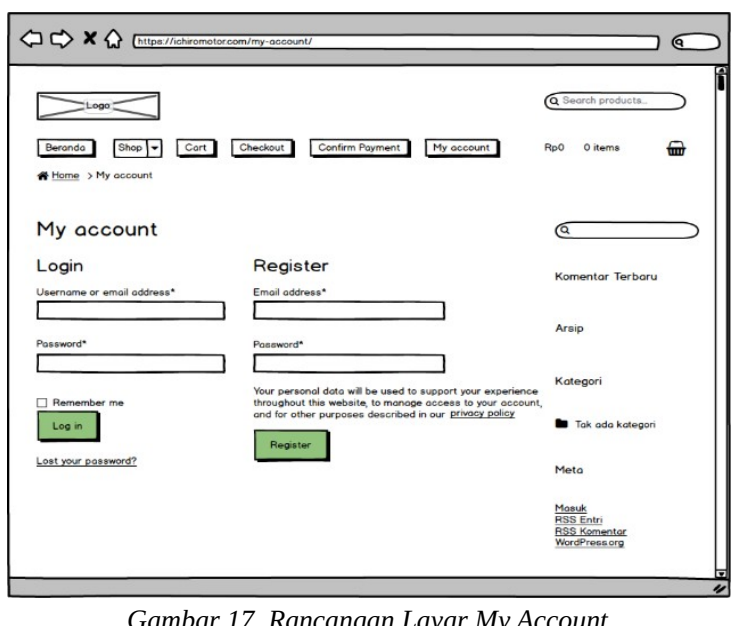

Pada gambar 17 merupakan Rancangan Layar My Account dari ichiro motor

c. Rancangan Layar Confirm Payment

Berikut adalah sebuah rancangan layar dimana pelanggan ingin membayar pesanan yang sudah dipesan sebelumnya :

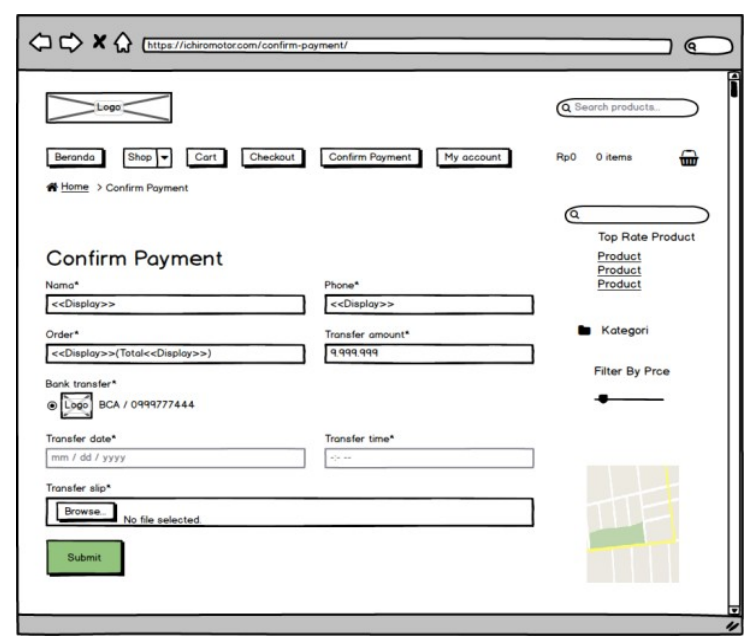

Gambar 18. Rancangan Layar Confirm Payment

Pada gambar 18 merupakan Rancangan Layar Confirm Payment dari Ichiro Motor

\subsection{Sequence Diagram}

Sequence diagram memaparkan secara detail rangkaian dari proses yang dilakukan dalam sistem untuk mencapai sebuah tujuan dari use case hubungan yang terjadi antar class, aktifitas apa saja yang terlibat, urutan antara aktifitas dan informasi 
yang diperlukan oleh masing-masing aktifitas. Berikut sequence diagram yang peneliti buat :

a. Sequence Registrasi

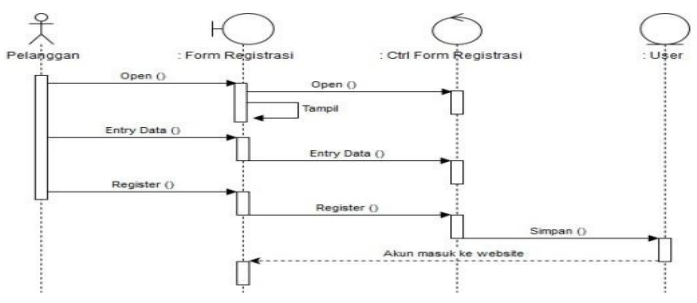

Gambar 19. Sequence Registrasi

b. Sequence Entry Login

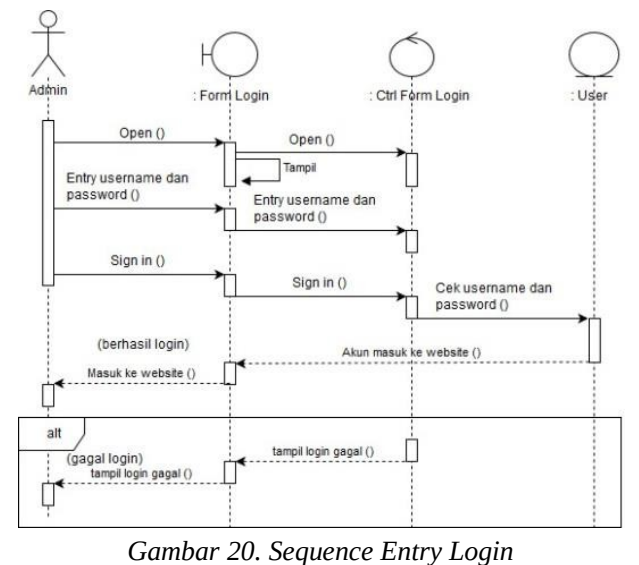

Pada gambar 20 merupakan sequence entry login dari ichiro motor

\section{KESIMPULAN}

Sesudah penulis menyelesaikan penelitian ini dan membuat website E-Commerce, maka akan dibuatkan kesimpulan sebagai bagian dari laporan penelitian yang telah dilaksanakan adalah sebagai berikut:

a. Dengan dibuatnya website e-commerce dengan berbasis content management system di Ichiro Motor dapat memudahkan dalam hal menjual produk, membuat laporan, serta memperluas area penjualan.

b. Dapat menampilkan informasi tentang toko, produk secara lengkap dan menarik bagi pelanggan.

c. Website yang mudah untuk digunakan (user friendly) baik dari sudut pandang pelanggan (front-end) maupun admin (back-end).

\section{DAFTAR PUSTAKA}

[1] Anggraeni, E.Y., Pengantar Sistem Informasi, Yogyakarta: ANDI, 2017.

[2] Tenia Wahyuningrum, Dwi Dwi Januarita, 'Implementasi dan Pengujian Web E-commerce untuk Produk Unggulan Desa', 2015, 57-66.

[3] Dewi, S.K., \& Garside, A. K. , Perancangan Website Sebagai Media Promosi dan Penjualan Pada Home Industry, 2014.

[4] Siregar, H. F. and Siregar, Y. H., 'Perancangan Aplikasi Komik Hadist Berbasis Multimedia', 2, 2018, pp. 113-121.

[5] Davis, G. B. , Kerangka Dasar Sistem Informasi Manajemen. Palembang: Maxikom, 2013.

[6] Muhammad, \& Ropianto, Pemahaman Penggunaan Unified Modelling Language . JT-IBSI, 1, 2016. 